\title{
Perceptions of the Importance of Sleep in Common Cold-Two Online Questionnaire-Based Surveys
}

\author{
Gill Phillipson ${ }^{1} \cdot$ Sue Aspley ${ }^{2} \cdot$ Ingo Fietze $^{3}$
}

Accepted: 1 April 2020 / Published online: 24 April 2020

(C) The Author(s) 2020

\begin{abstract}
Sleep deprivation affects the immune system and can render subjects more susceptible to symptoms associated with the common cold. The aim of this research was to investigate cold sufferers' and doctors' perceptions of the role of sleep in recovery from cold/flu. An online survey of 4000 adults who had suffered from cold/flu in the previous 12 months was conducted in eight countries and an online survey of 150 doctors was conducted in Germany. Responses were collected to questions regarding aspects of life affected by, and concerns while suffering from, cold/flu symptoms including nighttime awakening and actions taken to aid recovery. Responses were also collected to questions regarding advice given to cold/flu patients and the importance of sleep. Ability to sleep well was widely reported as negatively impacted by cold/flu (mean $46.1 \%$ of respondents across eight countries), especially in Western Europe, and inability to sleep well was a frequently reported concern associated with suffering from cold/flu (21.8\%). To sleep more than usual was a frequently reported action taken to feel better $(40.5 \%)$. Ninety-four percent of respondents reported waking up at night because of symptoms, cough being the most frequently reported symptom to awaken respondents. There was evidence of a possible relationship between sleep quality and medication taken at night for symptom relief. Countries with the highest proportions of respondents who reported sleep to be the aspect of life most negatively affected by a cold (France, Germany and Italy) were also those with the lowest proportions of respondents who reported that taking medications at night was the most effective way of getting back to sleep after waking due to cold symptoms. The majority of doctors believed sleep helped cold/flu patients to recover faster and that a good night's sleep was important. Sleep is widely considered to be important in promoting recovery from cold/flu. Hence, the relief of symptoms that disrupt sleep is also likely to be important for a faster recovery.
\end{abstract}

Keywords Sleep $\cdot$ Common cold $\cdot$ Flu $\cdot$ Nasal congestion $\cdot$ Cough

\section{Background}

To rest and seek more sleep when suffering from a cold is intuitive and commonly recommended by healthcare professionals (https://www.nhs.uk/conditions/common-cold/). However, the level of awareness of the possible role of sleep

This article is part of the Topical Collection on Medicine

Gill Phillipson

phillipson.g1@pg.com

1 Procter \& Gamble International Operations SA, Route de Saint-Georges 47, 1213 Petit-Lancy, Switzerland

2 Procter \& Gamble Technical Centres Ltd, 452 Basingstoke Road, Reading RG2 0QE, UK

3 Center of Sleep Medicine, Charité - Universitätsmedizin Berlin, Charitéplatz 1, 10117 Berlin, Germany in promoting recovery from a cold among sufferers is unknown. Sleep is necessary for general health and normal immune regulation [1]. Sleep deprivation has been associated with cognitive impairment, increased appetite and obesity, impaired glucose tolerance, reduced vaccine efficacy and cardiovascular disease [2]. Compared with results obtained the morning after sleeping from 11:00-07:00, experimental sleep deprivation (sleep restricted to the period 03:00-07:00) has been shown to significantly increase monocyte production of interleukin (IL) 6 and tumour necrosis factor (TNF) [3]. This enhanced inflammatory response is likely mediated by the nuclear factor $\mathrm{kB}$ inflammatory signalling system as well as via classic hormone and growth factor response pathways. Sleep deprivation has also been shown to have an impact on the expression of pro-inflammatory cytokine genes, inducing a greater than 3 -fold increase in transcription of IL-6 mRNA and a 2 -fold increase in TNF- $\alpha$ mRNA [3]. The role of cytokines in sleep is supported by 
the fact that some exhibit circadian rhythm. Pro-inflammatory cytokines such as TNF and IL-1 $\beta$ generally increase sleep, while anti-inflammatory cytokines generally inhibit sleep [4].

Since many medical conditions are associated with activation of cellular signals that initiate expression of inflammatory cytokines, sleep may have an important role in reducing the risk of acquiring such conditions. By extension, sleep may also affect the risk of developing symptoms after infection by agents that provoke an inflammatory response.

Two studies $[5,6]$ have shown that shorter sleep duration is associated with a greater susceptibility to the development of a cold after experimental infection with rhinovirus. In the former, 153 healthy volunteers reported their sleep efficiency (the percentage of time in bed that they were asleep) for the previous night on 14 consecutive days before receiving rhinovirus. Volunteers who had $<7 \mathrm{~h}$ sleep were 2.94 times more likely to develop cold symptoms than those who had $\geq 8 \mathrm{~h}$. Volunteers who had $<92 \%$ sleep efficiency were 5.50 times more likely to develop a cold than those with sleep efficiencies $\geq 98 \%$. Sleep efficiency, but not duration, was associated with total symptom score. In the second study, 164 healthy volunteers reported sleep duration over 7 consecutive days before receiving rhinovirus. Sleep duration was also assessed using wrist actigraphy. Compared with those sleeping $>7 \mathrm{~h}$ per night, volunteers whose actigraphy-assessed sleep duration was < $5 \mathrm{~h}$ were more likely to develop cold symptoms (odds ratio (OR) 4.50, 95\% CI 1.08-18.69), as were those sleeping 5-6 h (OR 4.24, 95\% CI 1.08-16.71). In neither study were the results explained by differences in pre-challenge virus-specific antibody, demographics, season of the year, body mass, psychological variables, or health practices. Although both studies involved experimental infection with rhinovirus, it is likely that the results are also applicable to natural colds. This is supported by the fact that peak symptom severity occurs at similar times in experimentally induced and naturally acquired colds [7].

Given the importance of sleep in regulating the immune system and the fact that the above-mentioned studies strongly suggest a causal role for sleep in cold susceptibility, sleep may also be an important factor in limiting symptoms and promoting colds recovery.

Also, there is surprisingly little experimental evidence to support this notion. Two studies in fruit flies suggest that increased sleep promotes survival during bacterial infection $[8$, 9]. Given the similarity in molecular components of fly and human innate immune responses, the results suggest that enhancing sleep will also aid recovery in human infection.

Since impairment of sleep can increase susceptibility to a cold, and cold symptoms can impair sleep, a cycle develops that must be broken in order to permit fast and efficient recovery.

\section{Objective}

To investigate cold/flu sufferer and doctors' perceptions of the relationship between sleep and common cold and to discuss the impact that appropriate symptom control can have in aiding restful sleep and improving recovery from the common cold.

\section{Method}

\section{Cold/Flu Sufferer Perception Survey}

An online survey in eight countries (France, Germany, Italy, Poland, Russia, Mexico, Brazil and the US) was conducted in 2016 to investigate experiences and practices relating to cold and flu. Approximately 500 adult participants, who reported that they had suffered from an episode of either cold or flu in the previous 12 months, were recruited from existing volunteer panels in each country. The methodology sought to represent the national demographic in terms of age, gender and region. The survey collected data relating to three key areas: cold and flu description (symptom severity and duration), impact of the cold on various aspects of the lives of the respondents and their families and action taken and remedies. Only those parts of the survey relating to sleep in the context of the common cold are presented in this communication.

\section{German Doctors Survey}

An online survey in which 150 German doctors (143 of whom described themselves as 'Allgemeinarzt/Internist' or General Practitioners) gave their opinions on the importance of sleep in recovering from a cold was conducted using an existing healthcare panel from the research provider Toluna.

\section{Main Outcome Measures}

The outcome measures in the cold/flu sufferer perception survey and the German doctors' survey are presented in Tables 1 and 2, respectively. No formal statistical comparisons were conducted.

\section{Results}

\section{Cold/Flu Sufferer Perception Survey}

The mean age of respondents ranged from 31.5 to 42.1 years. Approximately equal numbers of males and females were recruited in each country (Table 3). The results of those parts of the survey that included a question about sleep are summarised by country in Table 4 . The mean results of 
Table 1 Outcome measures relating to sleep in the cold/flu sufferer perception survey

Question

Which of the following aspects of your life are usually negatively impacted when you suffer from cold and flu symptoms?

Which of the following statements best describes the concerns you may think of overall when you suffer from cold or flu symptoms?

Which of the following activities help you the most to feel better when you are experiencing cold or flu symptoms?
Possible responses

-My ability to sleep well

-My ability to do my work

-My ability to enjoy my day

-My ability to engage in the household's daily activities

-My ability to exercise or maintain fitness regime

-My ability to interact with people

-My ability to play my role as a spouse/parent/partner

-None of the above; cold and flu symptoms do not usually impact my life negatively

-Not being able to perform as usual

-Not being able to sleep

-Not having the energy to wake up

-Passing my cold/flu onto others

-Not being able to concentrate

-The need to take a nap during the day

-The symptoms last too long

-Being too tired for my social life

-Not being in a good mood

-Not being able to enjoy time with family/friends

-The impact on the other household members' routine

-The symptoms might affect my personal appearance

-My symptoms could develop into something worse

-The symptoms might affect others' perceptions of me

-Being forgetful

-Not being able to look after my appearance

-Other

-None of the above

-Drink something warm (infusion, tea, soup)

-Get more sleep than usual

-Take vitamins

-Go through the day as if it was a normal day

-Avoid cold temperatures/cold weather

-Avoid demanding activities such as work, household tasks or exercise

-Watch TV or a movie

-Feel the warm effect of ingredients derived from plants

-Keep away from any noise

-Drink cool fluids, water, juice etc.

-Get a hug from a beloved one

- Get fresh air

-Back rub or massage

-Exercise my body/keep my body active

-Feel the fresh effect of essential oils/medicinal herbs

-Have a healthy diet made of fresh food

-Have somebody taking care of me (friend or family)

-Avoid bright light/sunshine

-Eat my favourite food

-Listen to soft music

-Listen to music I usually enjoy all year long 
Table 1 (continued)

\begin{tabular}{|c|c|}
\hline Question & Possible responses \\
\hline & -Listen to the radio \\
\hline & -Read or book or a magazine or a newspaper \\
\hline & -Go for bright light/sunshine \\
\hline & •Others \\
\hline & -None of the above \\
\hline \multirow{3}{*}{$\begin{array}{l}\text { When you suffer from cold or flu symptoms, how many } \\
\text { times a night do you usually wake up due to the symptoms? }\end{array}$} & $\bullet 1-2$ \\
\hline & $\cdot 3-5$ \\
\hline & $\bullet 6$ \\
\hline \multirow[t]{11}{*}{ Which cold or flu symptom is most likely to awaken you at night? } & $\cdot$ Cough \\
\hline & $\cdot$ Runny, dripping nose \\
\hline & -Sinus/nasal congestion and/or pain \\
\hline & •Sore throat \\
\hline & •Headache \\
\hline & -Sneezing \\
\hline & •Fever \\
\hline & -Chest congestion and/or pain \\
\hline & -Body or muscle aches \\
\hline & •Other \\
\hline & -None of the above, I do not wake up at night \\
\hline \multirow{9}{*}{$\begin{array}{l}\text { When you wake up during the night due to your cold or flu } \\
\text { symptoms, what are the most effective actions you } \\
\text { would usually take to get back to sleep? }\end{array}$} & -Staying in bed and just waiting until I go back to sleep \\
\hline & -Watching TV or reading a book \\
\hline & -Surfing the internet/apps on my mobile/tablet \\
\hline & •Checking my emails \\
\hline & -Checking my social media \\
\hline & -Taking some sleep medicine \\
\hline & -Taking my cold or flu treatment for symptom relief \\
\hline & -Listening to music \\
\hline & •Drinking something \\
\hline
\end{tabular}

questions 1, 2 and 3 are shown in Figs. 1, 2 and 3, respectively. When asked which aspects of their lives were usually negatively impacted when suffering from cold/flu symptoms, the proportion of respondents who reported that their ability to sleep well was impacted ranged from $63 \%$ in France to $25 \%$ in Russia. The aspect of life that was most affected was the ability to sleep well in France and Italy and the ability to work in all other countries. In Germany, Mexico, Brazil and the US, the ability to sleep well was the second most affected aspect of life, while in Poland and Russia it was the fourth and fifth most affected aspect, respectively. When asked to indicate which statement best described the concerns they thought of overall when suffering from cold/flu symptoms, the proportion of respondents who selected the statement 'Not being able to sleep' ranged from $34 \%$ in France to $7 \%$ in Russia. 'Not being able to sleep' was one of the top three concerns in six of the eight countries, the exceptions being Poland and Russia. When asked about the activities (apart from taking medicines) that usually helped them the most to feel better when experiencing cold or flu symptoms, the proportion of respondents who selected 'Get more sleep than usual' ranged from $55 \%$ in Germany to $21 \%$ in Brazil. In all countries except Brazil, 'Get more sleep than usual' was the second most frequently reported activity, the most frequently reported being 'Drink something warm (infusion, tea, soup)', an action that can also promote sleep. In Brazil, 'Get more sleep than usual' was the fourth most frequently reported activity.

In all countries, at least $90 \%$ of respondents reported waking up at night because of symptoms and 40-50\% woke 3-5 times, with the exception of Russia, where $25 \%$ woke 3-5 times per night. In all countries, 4-8\% of respondents woke at least six times per night. Cough was the most frequently reported symptom to keep the respondents awake at night in all countries, the proportion that reported cough ranging from $42 \%$ in the US to $26 \%$ in Brazil. In six countries (Germany, Italy, Russia, Mexico, Brazil and the US), the second most commonly reported symptom that woke respondents was 'sinus/nasal congestion and/or pain’ (19-26\% of respondents). 
Table 2 Outcome measures in the German doctors survey

\begin{tabular}{|c|c|}
\hline Question & Possible responses \\
\hline $\begin{array}{l}\text { When you see a patient suffering from cold or flu } \\
\text { what is first thing you always advise they do? }\end{array}$ & $\begin{array}{l}\cdot \text { Sleep } \\
\cdot \text { Rest } \\
\cdot \text { Hydrate } \\
\cdot \text { Take vitamins } \\
\cdot \text { Eat well } \\
\cdot \text { Drink a hot drink } \\
\text {-Take an analgesic } \\
\text {-Take a cold/flu medicine (all forms) } \\
\cdot \text { Something else (free text) }\end{array}$ \\
\hline $\begin{array}{l}\text { Do you believe sleep helps your patients suffering } \\
\text { cold/flu recover faster? }\end{array}$ & $\begin{array}{l}\cdot \text { Strongly agree } \\
\cdot \text { Agree } \\
\cdot \text { Neither agree or disagree } \\
\cdot \text { Disagree } \\
\cdot \text { Strongly disagree }\end{array}$ \\
\hline $\begin{array}{l}\text { How important is a good night's sleep when your } \\
\text { patients are suffering from cold/flu? }\end{array}$ & $\begin{array}{l}\text {-Very important } \\
\text {-Important } \\
\text { •Neither important nor unimportant } \\
\text { •Rather unimportant } \\
\text { - Not unimportant }\end{array}$ \\
\hline $\begin{array}{l}\text { What is the scientific rational for sleep being } \\
\text { good for cold/flu? Please be as specific as possible (free text) }\end{array}$ & \\
\hline
\end{tabular}

In five of these six, 'runny, dripping nose' was the third most frequently reported symptom to cause awakening (8-19\% of respondents), whereas fever was the third most frequently reported symptom that did so in Russia (8\%). In France and Poland, 'runny, dripping nose' was the second most commonly reported symptom that woke respondents (17\% and $21 \%$ of respondents, respectively), followed by 'sinus/nasal congestion and/or pain' (16\% and $18 \%$ of respondents, respectively). The mean results across all eight countries regarding the number of times respondents awoke due to symptoms are shown in Fig. 4 and the mean contribution of each symptom is shown in Fig. 5. The proportion of respondents who reported using cold or flu medication at night for symptom relief ranged from $52 \%$ in Russia to $24 \%$ in Italy.

Since respondents were required to have had experienced a cold within the year preceding participation in the survey, as opposed to having a cold while participating, no data are available regarding the time interval between experiencing the cold and either sleep disturbance or recovery.

\section{German Doctors Survey}

The four most commonly reported advisory actions given by the doctors to patients suffering from cold or flu were 'Rest', 'Hydrate', 'Take a cold/flu medicine' and 'Sleep' (approximately $41 \%, 21 \%, 17 \%$ and $7 \%$, respectively). All other responses were selected by less than $5 \%$ of respondents. The majority of doctors (93\%) believed that sleep helped their patients suffering from cold/flu recover faster, selecting either 'Strongly agree' or 'Agree'. Almost all doctors (95\%) considered it important that their patients got a good night's sleep when suffering from cold or flu, selecting either 'Very important' or 'Important'. No respondent selected 'Very unimportant'. When asked about the scientific rationale for sleep being
Table 3 Demographics of respondents in the cold/flu sufferer perception survey

\begin{tabular}{lcccccccc}
\hline & FR & GE & IT & PO & RU & ME & BR & US \\
\hline Number of respondents & 503 & 501 & 502 & 500 & 502 & 500 & 500 & 500 \\
\% males & 48 & 50 & 50 & 50 & 50 & 51 & 50 & 50 \\
Mean age (years) & 41.6 & 42.1 & 41.7 & 40.3 & 40.0 & 31.5 & 34.3 & 40.7 \\
Standard deviation & 13.8 & 13.7 & 13.3 & 14.0 & 11.9 & 9.4 & 10.8 & 13.8 \\
\hline
\end{tabular}

FR, France; GE, Germany; IT, Italy; $P O$, Poland; $R U$, Russia; $M E$, Mexico; $B R$, Brazil; US, United States 
Table 4 Perceptions of the relationship between sleep and common cold from the cold/flu sufferer perception survey

Question FR GE IT PO RU ME BR US Percentage of respondents

'My ability to sleep well' in response to the question 'Which of the following aspects of your life are usually negatively impacted when you suffer from cold and flu symptoms?'

'Not being able to sleep' in response to the question 'Which of the following statements best describes the concerns you may think of overall when you suffer from cold or flu symptoms?'

'Get more sleep than usual' in response to the question 'Which of the following activities usually help you the most to feel better when you experience cold or flu symptoms?'

Awaken at night because of symptoms

Awaken 3-5 times per night

Awaken $\geq 6$ times per night

'Cough' in response to the question 'What cold or flu symptoms are usually most likely to awaken you at night?'

'Runny, dripping nose' in response to the question 'What cold or flu symptoms are usually most likely to awaken you at night?'

'Sinus/nasal congestion and/or pain' in response to the question 'What cold or flu symptoms are usually most likely to awaken you at night?'

'Taking my cold or flu treatment for symptom relief' in response to the question 'When you wake up during the night due to your cold or flu symptoms, what are the most effective actions you would usually take to get back to sleep?'

$\begin{array}{rrrrrrrr}63 & 50 & 60 & 30 & 25 & 47 & 47 & 47 \\ 34 & 23 & 26 & 12 & 7 & 24 & 20 & 28 \\ 42 & 55 & 30 & 48 & 48 & 35 & 21 & 45 \\ 96 & 93 & 90 & 94 & 92 & 96 & 96 & 96 \\ 48 & 40 & 40 & 40 & 23 & 39 & 43 & 47 \\ 8 & 5 & 5 & 5 & 4 & 5 & 5 & 4 \\ 37 & 39 & 35 & 30 & 36 & 31 & 26 & 42 \\ 17 & 8 & 9 & 21 & 6 & 15 & 19 & 10 \\ 16 & 26 & 19 & 18 & 25 & 19 & 21 & 19 \\ 35 & 33 & 24 & 40 & 52 & 37 & 39 & 39\end{array}$

$F R$, France; $G E$, Germany; IT, Italy; $P O$, Poland; $R U$, Russia; $M E$, Mexico; $B R$, Brazil; $U S$, United States

good for cold/flu, approximately $50 \%$ mentioned its effects on the immune system, such as 'Resting the body leads to a better immune system', 'The immune system can regenerate', 'The immune system is more efficient in the sleep phase in eliminating the virus than in the wake phase' and 'The body can concentrate on the defense of the pathogenic agents. In addition, 'the patient is less stressed while sleeping'.

\section{Discussion}

The cold/flu sufferer perception survey showed that sleep is commonly disrupted by symptoms and that sufferers are often concerned about inability to sleep. The fact that one of the most frequently reported activities undertaken was to get more sleep shows that many people believe sleep aids recovery. The majority of respondents woke during the night, cough being the most frequently reported symptom that woke them. The results do not permit an evaluation of the effect of age or comorbidity on the perception of sleep disturbance because results were not analysed separately for each age category and respondents' comorbidities were not collected.

The proportion of respondents who reported that ability to sleep well was the aspect of life most negatively affected by a cold was lowest in Poland and Russia. These countries also had the lowest proportion of respondents who reported that
Fig. 1 Mean response to the question 'Which of the following aspects of your life are usually negatively impacted when you suffer from cold and flu symptoms?'

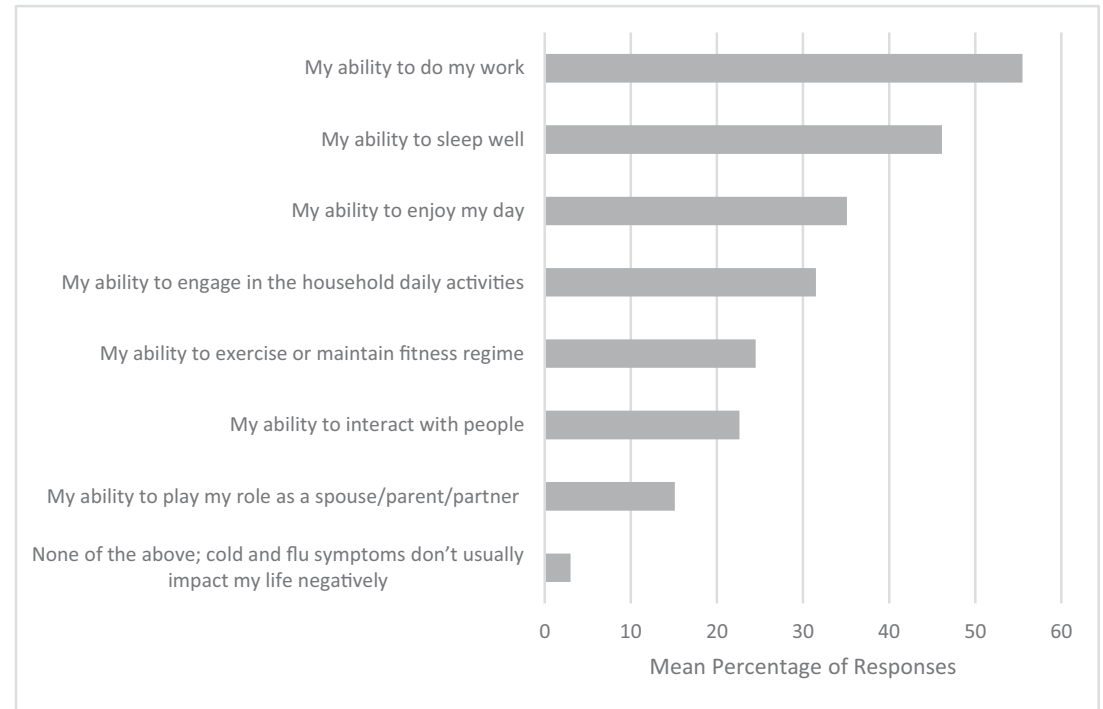


Fig. 2 Top ten mean responses to the question 'Which of the following statements best describes the concerns you may think of overall when you suffer from cold or flu symptoms?'

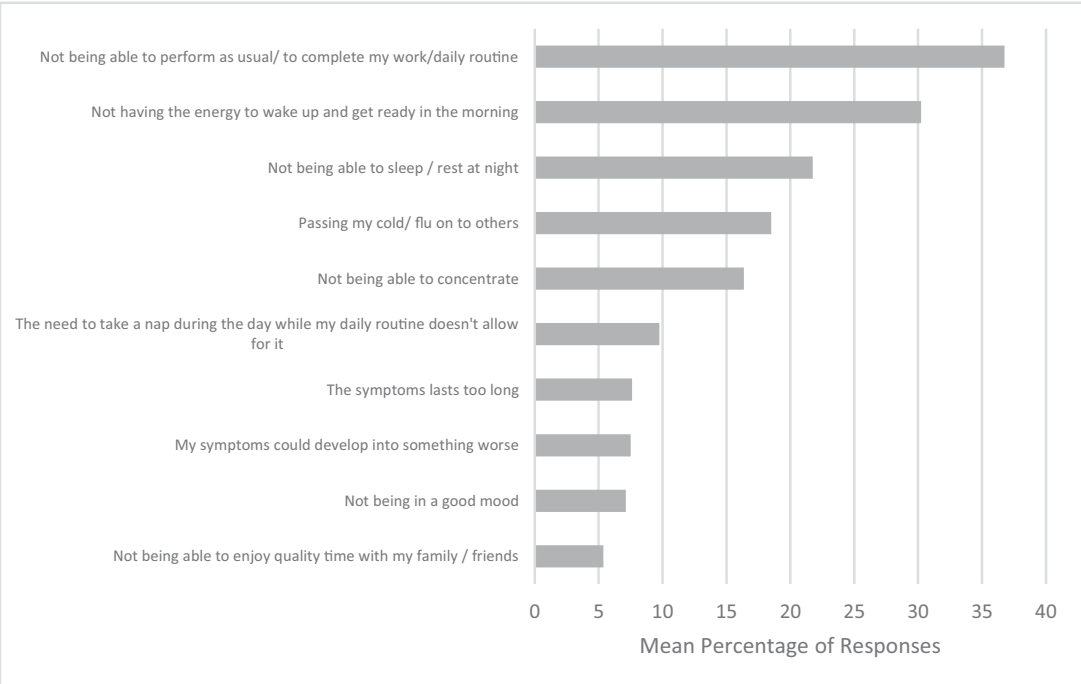

not being able to sleep was one of their greatest concerns when suffering from a cold. It is possible that a lower awareness and perceived importance of sleep disorders in these countries compared with Western European countries could have contributed to the different results. In all countries, better education of patients regarding the importance of sleep during a cold would be advantageous.

The results of the cold/flu sufferer perception survey are generally consistent with those of a similar previously conducted survey in 3019 participants [10]. In that study, $23 \%$ of participants attributed their infection to insufficient sleep and the two most commonly reported actions were taking over-the-counter (OTC) remedies (40\%) and getting sufficient rest/sleep (39\%). Sixty-six percent reported having used multi-ingredient products to control symptoms. When asked the reason for OTC use, $33 \%$ gave 'To get a good night's sleep' as the reason. Overall, participants reported waking up approximately twice per night due to symptoms while experiencing a respiratory illness. When asked about their concerns regarding infection, $12 \%$ said that 'Being able to sleep or rest at night' was a concern.

Cough, nasal congestion and catarrh are irritating symptoms that cause discomfort and may disrupt sleep. Hence, relief of symptoms would be expected not only to relieve discomfort but also to facilitate sleep, perhaps allowing the body to moderate its inflammatory response, thus further reducing symptoms. Evidence of a possible relationship between sleep quality and nighttime use of cold/flu medication was seen in the cold/flu sufferer perception survey. The three countries with the highest proportions of respondents who reported sleep to be the aspect of life most negatively affected by a cold were also those with the lowest proportions of respondents who reported that taking medications at night was the most effective way of getting back to sleep after waking due to cold symptoms. Russia had the lowest proportion of respondents who reported sleep to be most negatively impacted, the lowest proportion who woke 3-5 times per night due to
Fig. 3 Top ten mean responses to the question 'Which of the following activities usually help you the most to feel better when you experience cold or flu symptoms?'

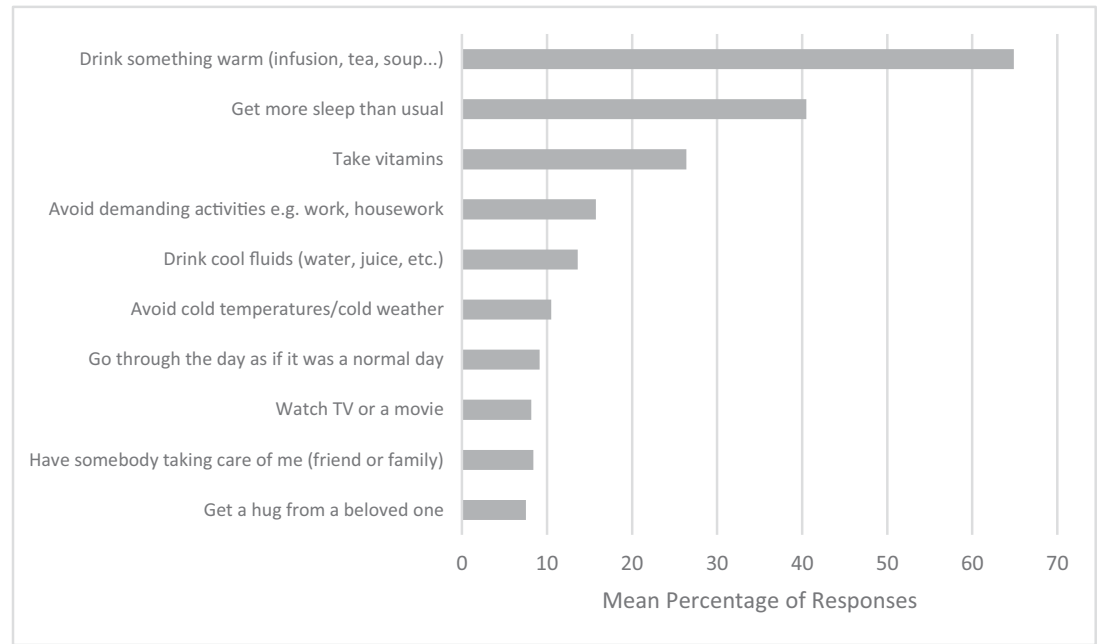




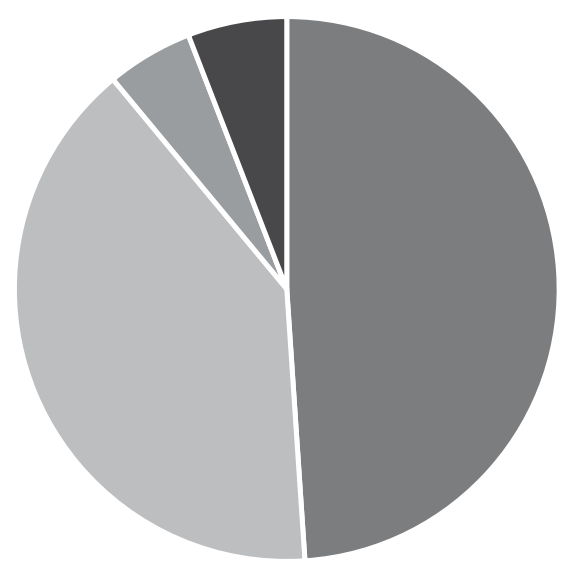

- 1-2 times per night

- 3-5 times per night

- $6+$ times per night

- Cold and flu symptoms usually do not wake me up at night

Fig. 4 Mean response for number of times respondents usually wake up at night due to cold or flu symptoms

symptoms and the highest proportion who considered taking cold or flu medication at night to be most effective.

Paul (2010) found that children treated with an ointment containing levomenthol, camphor, turpentine oil and eucalyptus oil slept significantly better than those who received petrolatum and those who received no treatment, due to symptom relief [11]. Since the actives in the ointment are not known sedatives, it is more likely that perception of improved sleep was due to symptom relief than to a direct effect on sleep. Similar results in adults were obtained by Santhi et al. (2017), who conducted a randomised, single-blind, placebo- controlled study to investigate the effects of the same ointment on sleep in adult patients experiencing cough, nasal congestion and sleep disturbance [12]. The product was significantly superior to placebo in terms of participants' perceptions of sleep quality and the extent to which they felt refreshed and well-rested on waking. In an uncontrolled observational trial in which 300 participants with acute rhinitis received a nasal spray containing the decongestant tramazoline, $97.4 \%$ reported an improvement in quality of sleep [13]. Although these studies all indicate that improved symptom control can enhance sleep, it should be noted that the process may differ between children and adults.

In addition to facilitating sleep by reducing symptoms, multi-ingredient cold and flu remedies that contain a first generation antihistamine may also induce sleep directly. The effectiveness of such a multi-ingredient product in improving various symptoms and ability to sleep was shown in a randomised, placebo-controlled study [14]. In that study, 485 patients with a cold received an evening dose of a product containing paracetamol, dextromethorphan hydrobromide, ephedrine suphate and doxylamine succinate or placebo and assessed nasal congestion, runny nose, cough and pain, $3 \mathrm{~h}$ after administration and within $1 \mathrm{~h}$ of arising the following morning. Compared with placebo, patients who received the multi-ingredient product had significantly greater agreement that they slept as well as they usually did when they were free of a cold. In addition, this study demonstrated that the multiingredient product was significantly more efficacious than placebo in terms of composite and individual symptom scores. Nighttime sleep aids containing only antihistamines may also help the body combat the symptoms of the common cold by facilitating sleep, although studies have shown mixed results. A study in which children with infection-induced cough received diphenhydramine at bedtime showed that the extent to
Fig. 5 Mean response to the question 'Which cold or flu symptom is most likely to awaken you at night?'

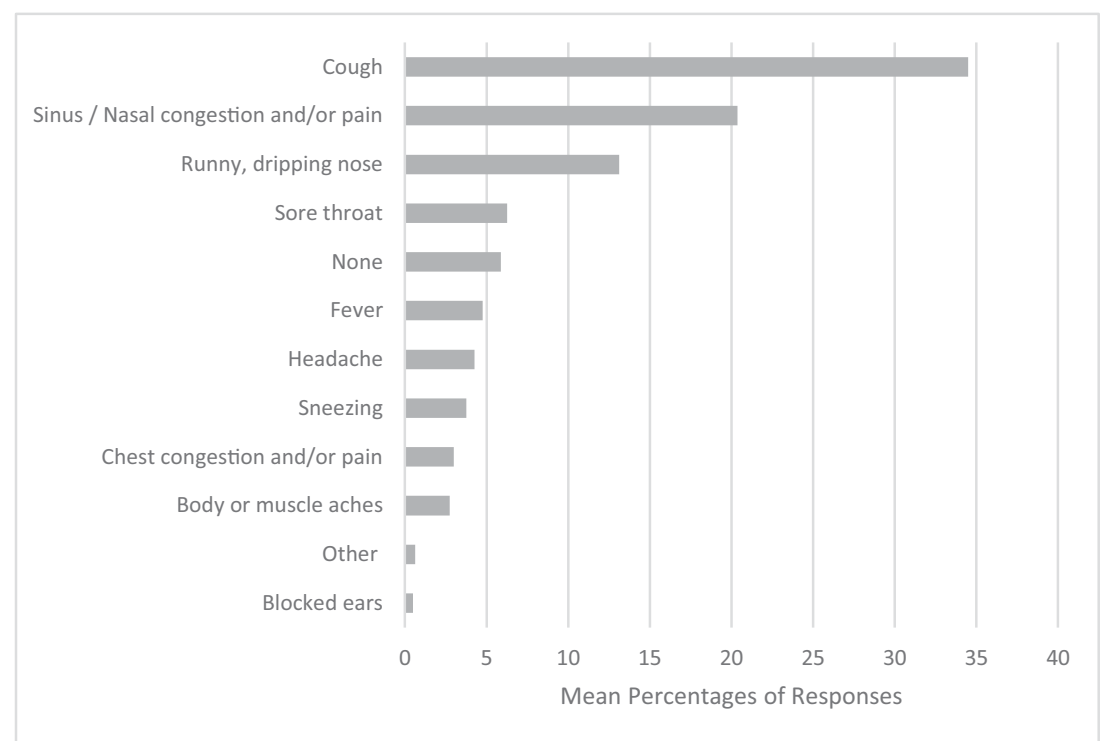


which cough had affected children's ability to sleep was significantly decreased compared with baseline [15]. However, another study suggested that diphenhydramine and dextromethorphan were not superior to placebo in terms of improving cough relief in children [16]. In a comparison of honey, dextromethorphan and no treatment, neither honey nor dextromethorphan were significantly superior to no treatment in terms of children's sleep quality [17]. In a study in which children received either polysaccharide-resin-honey paediatric cough syrup (PRH syrup) or carbocysteine syrup [18], the improvement in sleep quality was significantly greater with the PRH syrup. Although the role of medicines that directly promote sleep remains unclear, it seems intuitive that they should not be recommended to improve sleep that is disturbed by cold symptoms. The relief of symptoms to improve sleep is the preferred action.

It is encouraging that over $90 \%$ of respondents in the German doctors survey believed that sleep aided recovery from a cold and that over $90 \%$ considered it important that their cold and flu patients got a good night's sleep. Approximately half mentioned the association between sleep and the immune system. However, the interactions between the brain and the immune system in sleep are complex [19] and the precise mechanisms by which sleep may bring about faster recovery are only just being elucidated. Not only does sleep deprivation affect the immune system but, conversely, the immune system affects the sleep architecture. Inflammatory mediators and neurotransmitters released as a result of infection interact to affect the regulation of sleep, possibly promoting recovery $[2,20]$. Infection-induced alteration in sleep architecture might aid recovery by facilitating the development of fever, which is known to increase survival during bacterial and viral infections. During infection, there is generally an increase in non-REM sleep (although this is more fragmented than normal) and a decrease in REM sleep, thus reducing overall energy expenditure. Although the extent to which changes in sleep architecture affect clinical outcome during infection is unknown, any such necessary changes in sleep could not be achieved in individuals whose troublesome symptoms are sufficiently severe to prevent sleep.

Even with minor infections such as a cold, sleep architecture is altered. Drake (2000) found that individuals with experimentally induced cold symptoms had average reductions per night of $23 \mathrm{~min}$ in total sleep time, $36 \mathrm{~min}$ in consolidated sleep time (total sleep time excluding non-REM stage 1 sleep) and 5\% in sleep efficiency during the active phase of the cold compared with the incubation period [21]. These changes were significantly greater than those observed in asymptomatic individuals. While it is possible that these symptoms may have inhibited sleep, the absence of a consistent correlation between symptoms and sleep latency suggests this was not likely.

The main limitation of the cold/flu sufferer perception survey was that respondents were not experiencing a cold at the time of participation and may therefore not remember accurately how they felt and what actions they took during their last cold. However, the fact that the survey involved a large number of respondents across eight countries gives it a robustness that permits general conclusions to be drawn regarding perceptions of the role of sleep in recovery from a cold. The benefits of more sleep, achieved by taking medication to decrease symptoms that disrupt sleep, should be emphasised by healthcare professionals. Further studies should be conducted to look at the relationship between amount (and type) of sleep and the time to recovery from a cold in order to determine whether general perceptions are supported by clinical evidence.

\section{Conclusion}

The results of the cold/flu sufferer perception survey and the German doctors survey are generally consistent with previously published survey results suggesting that obtaining a good night's sleep is widely considered to be important in promoting recovery from a cold or flu. Moreover, not getting sufficient sleep is a significant concern among many people suffering from cold and flu symptoms. Multiingredient OTC cold and flu remedies have been shown to facilitate sleep by relieving symptoms that disrupt sleep and, in the case of those formulations containing a first-generation antihistamine, possibly by directly affecting sleep. The appropriate treatment of symptoms during a cold is therefore important to promote recovery. The commonly held belief that sleep is beneficial in aiding recovery from a cold appears to be supported by recent research concerning the relationship between sleep and the immune system.

Acknowledgements The authors gratefully acknowledge the assistance of the research agencies Ipsos (https://www.ipsos.com) and Toluna (www.toluna.com) for help in study execution.

Funding Information This work was sponsored in full by Procter \& Gamble Personal Health Care International.

\section{Compliance with Ethical Standards}

Conflict of Interest At the time of preparing this manuscript, SA and GP were full-time employees of The Procter \& Gamble Company and may have stock and/or stock options in the company. IF declares consultancy fees from Procter \& Gamble. All attributed authors participated in the development and review of this manuscript.

Open Access This article is licensed under a Creative Commons Attribution 4.0 International License, which permits use, sharing, adaptation, distribution and reproduction in any medium or format, as long as you give appropriate credit to the original author(s) and the source, provide a link to the Creative Commons licence, and indicate if changes were made. The images or other third party material in this article are included 
in the article's Creative Commons licence, unless indicated otherwise in a credit line to the material. If material is not included in the article's Creative Commons licence and your intended use is not permitted by statutory regulation or exceeds the permitted use, you will need to obtain permission directly from the copyright holder. To view a copy of this licence, visit http://creativecommons.org/licenses/by/4.0/.

\section{References}

1. Born J, Lange T, Hansen K, et al. Effects of sleep and circadian rhythm on human circulating immune cells. J Immunol. 1997;158: 4454-64.

2. Imeri L, Opp MR. How (and why) the immune system makes us sleep. Nat Rev Neurosci. 2009;10(3):199-210.

3. Irwin MR, Wang M, Campomayor CO, Collado-Hidalgo A, Cole S. Sleep deprivation and activation of morning levels of cellular and genomic markers of inflammation. Arch Intern Med. 2006;166(16): 1756-62.

4. Bryant PA, Trinder J, Curtis N. Sick and tired: does sleep have a vital role in the immune system? Nat Rev Immunol. 2004;4:45767.

5. Cohen S, Doyle WJ, Alper CM, Janicki-Deverts D, Turner RB. Sleep habits and susceptibility to the common cold. Arch Intern Med. 2009;169(1):62-7.

6. Prather AA, Janicki-Deverts D, Hall MH, Cohen S. Behaviorally assessed sleep and susceptibility to the common cold. Sleep. 2015;38(9):1353-9.

7. Gwaltney JM, Hendley JO, Patrie JT. Symptom severity patterns in experimental common colds and their usefulness in timing onset of illness in natural colds. Clin Infect Dis. 2003;36(6):714-23.

8. Kuo TH, Williams JA. Increased sleep promotes survival during a bacterial infection in Drosophila. Sleep. 2014;37(6):1077-86.

9. Kuo TH, Williams JA. Acute sleep deprivation enhances postinfection sleep and promotes survival during bacterial infection in drosophila. Sleep. 2014;37(5):859-69.

10. Hull JD, Barton IP, Torgersen J, et al. A survey of the experience and impact of acute upper respiratory tract infections on people in six countries in the 2011/2012 common cold and flu season. Open J Respir Dise. 2013;3:175-87.

11. Paul I, et al. Vaporub, petrolatum and no treatment for children with nocturnal cough and cold symptoms. Paediatrics. 2010;126:108298.
12. Santhi N, Ramsey D, Phillipson G, et al. Efficacy of a topical aromatic rub (Vicks VapoRub®) on effects on self-reported and actigraphically assessed aspects of sleep in common cold patients. Open J Respir Dis. 2017;7:83-101.

13. Katona G, Sultész M, Farkas Z, et al. Treatment of acute rhinitis with a nasal spray containing tramazoline and essential oils: a multicenter, uncontrolled, observational trial. Clin Transl Allergy. 2015;5:38

14. Mizoguchi H, Wilson A, Gerdack DR, Hull JD, Goodale M, Grender JM, et al. Efficacy of a single evening dose of a syrup containing paracetamol, dextromethorphan hydrobromide, doxylamine succinate and ephedrine sulphate in subjects with multiple common cold symptoms. Int J Clin Pharmacol Ther. 2007;45: 230-6.

15. Ayazi P, Mahyar A, Yousef-Zanjani M, Allami A, Esmailzadehha $\mathrm{N}$, Beyhaghi T. Comparison of the effect of two kinds of Iranian honey and diphenhydramine on nocturnal cough and the sleep quality in coughing children and their parents. PLoS One. 2017;12(1): e0170277.

16. Paul IM, Yoder KE, Krowell KR, et al. Effect of dextromethorphan, diphenhydramine, and placebo on nocturnal cough and sleep quality for coughing children and their parents. Pediatrics. 2004;114(1): e85-90.

17. Paul IM, Beiler J, McMonagle A, Shaffer ML, Duda L, Berlin CM Jr. Effect of honey, dextromethorphan, and no treatment on nocturnal cough and sleep quality for coughing children and their parents. Arch Pediatr Adolesc Med. 2007;161(12):1140-6.

18. Cohen HA, Hoshen M, Gur S, et al. Efficacy and tolerability of a polysaccharide-resin-honey based cough syrup as compared to carbocysteine syrup for children with colds: a randomized, singleblinded, multicenter study. World J Paediatr. 2017;13(1):27-33.

19. Marshall L, Born J. Brain-immune interactions in sleep. Int Rev Neurobiol. 2002;52:93-131.

20. Opp MR, Born J, Irwin MR. Sleep and the immune system. In: Ader R, editor. Psychoneuroimmunology. 4. New York: Academic Press; 2007. p. 579-618.

21. Drake CL, Roehrs TA, Royer H, Koshorek G, Turner RB, Roth T. Effects of an experimentally induced rhinovirus cold on sleep, performance, and daytime alertness. Physiol Behav. 2000;71(1-2):7581.

Publisher's Note Springer Nature remains neutral with regard to jurisdictional claims in published maps and institutional affiliations. 